\title{
Future Internet of Things Architecture to Industrial Perspective
}

\author{
Muhammad Tahzeeb ul \\ Hassan \\ University of Agriculture \\ Faisalabad \\ Pakistan
}

\author{
Mubashir Tariq \\ University of Central Punjab \\ Faisalabad \\ Pakistan
}

\author{
Sania Anwar \\ UAF \\ Pakistan
}

\author{
Noman Tahir \\ National Textile University Faisalabad, Pakistan \\ Pakistan
}

\begin{abstract}
The idea behind exertion to build up remote device organize framework to persistently screen and identify cardiovascular poison accomplished patients by the side of isolated regions. A remote sensor framework intended toward persistently catches and communicates the ECG signs to the patient's device. Internet of Things (IoT) is a conventional element of life by raising the communication and networking anytime, anyplace. Security requirements for IoT is most likely emphasize the importance of precisely start, operate, and forced security arrangement for the duration of their life-cycle. The key of the exploration is basically to concentrate on health related to sensors and monitors to keep track of critical signs by using smart clothes. The aim is to make a framework where diverse sorts of sensors is coordinate into textiles to be utilized as a part of constant checking by people utilizing adaptable and wearable frameworks. The consequences from the administer used to formulate analysis and to detect movement in order to sustain the people to keep away from heart threat reason and help to avoid heart attack and other discriminating actions. Micro sensors embedded all through the shirt that proficient to monitor data. The primary thought of this to discover the possibility of performing dependable respiratory administers by a method for garments raised area.
\end{abstract}

\section{Keywords}

WSN, RTM, Cardiovascular disease, ECG, Cellular Network.

\section{INTRODUCTION}

The world is encountering high rate of Heart diseases. Heart diseases have turned out to be the main sources of passing, the Health Organization expresses heart illnesses are the biggest destroyers, stressing 16.1 thousand lives per year[5].

Optical wave controllers and optical strands are when in distrust comprehensively examined for the use in recognizing systems (Paul et al. 2012, Culs et al.2008, Yoo et al. 2010, Tai et al. 2014, Xiuchen et al. 2014). To change and following expansive scale assembling of optical parts, fiber optic sensor development has gone to a level of industrialization.

In this, a fiber Bragg grating sensor was utilized in the meantime screen and measure heartbeat and breath rates using a leaving fiber Bragg grating sensor. The typical used here look like the current electrical/electronic heartbeat and respiratory rate sensors which is to perceive the expansion of the heart controls (Yoo et al. 2010, Jean et al. 2010, Wehr et al. 2001).

\author{
Muneeb Niaz \\ University of Central Punjab Faisalabad \\ Pakistan
}

The Internet of things (IoT) decides the utilization of perceptively related gadgets and frameworks to influence information gathered by installed sensors and actuators in machines and other physical items. Io T is likely to increase quickly in the coming years and this meeting will unleash another measurements of administrations that build the personal satisfaction of buyers and proficiency of events, opening that the GSMA calls the 'Associated Life'. For customers, the IoT has the possibility to take activities that impressively enhance asset efficiency, security, comfort, training and frequent more parts of day by day life.

This section gives an outline of related work in the fields of Wearable Computing, Computational Garment Design and style, Embedded Devices, Fuzzy Reason, and Computational Literacy. In the most recent decade, individualized computing advancements have ended up pervasive. Clothing has of late been utilized to change the body and adjust our understandings of self and the human structure for quite a while. Electronic gadgets have turned out to be progressively versatile, compact, and open, in their physical structure. This has made the likelihood of consistent or pervasive processing access for the client, for the most part through lightweight advancements: pocket-sized mobile phones palm-top PCs. Every gadget these days supports different estimation and correspondence advancements. These gadgets to give a few case, for instance, cell phones, sensors, estimation gadget and tablets now are a bit of ordinary life. The small capacity of these devices is that they will organize with each other through a framework, for instance, the web. The relationship close by these devices permit them to accomplish the general target [9].

Two smart dress system models, in perspective of conductive shield method, totally experienced. The principle model contained one recognizing fragment, and the outcome shows that the sense pieces of clothing structure could reasonably watch the subjects' breathing case among sitting, standing, and assorted sorts of running. The structure has furthermore settled to be significant in the recognition which can track heart rate, temperature, circulatory strain rest upon issue symptoms. The second model included two recognizing segments. Beside each one of the characteristics of the fundamental model system, a structure with two identifying segments can be used to choose the relationship between the rib enclosed in area and automatic partitions, which offer information to particular conditions, e.g., heart arrhythmias [15].

This work proposes a remote sensor organize for continuous checking and identification cardiovascular diseases. 
This framework rages remote sensor arrange innovation with different remote developments, for example, cell organize, remote LAN, and broadband system, for productive and quick transference of security alarms. This proposed framework comprises wearable remote sensor framework, controller framework, assorted remote system framework, there are dual stage ongoing information investigation and representation framework, and the sign framework. Completely they will give the Signals examination [10] of cardiovascular patient, isolated observing, transference attention to specialist, comparative, to clinic, an expanded administration exchanging the ecg signals and previous records of patient towards specialist in a controlled area. Framework container used for giving advanced social coverage administrations to the country regions of the creating nations that are opposing deficiency of expert precise specialists. In this manner the cardiovascular disease bringing passing of persevering can reduce vastly usage of this proposed framework.

A list of some commercial products and their principal applications is presented in Table 1

\begin{tabular}{|c|c|c|c|}
\hline Product Name & Monitored Parameters & $\begin{array}{l}\text { Wireless } \\
\text { Platform }\end{array}$ & Battery Type \\
\hline $\begin{array}{l}\text { Hex Oskin, Biometric } \\
\text { Shirt }\end{array}$ & $\begin{array}{l}\text { Heart rate (HR), HR variability, respiratory } \\
\text { rate, number of steps, distance traveled, } \\
\text { pace, maximal oxygen consumption, and } \\
\text { calories burned }\end{array}$ & Bluetooth & $\begin{array}{l}5-6 \text { days (star } \\
14+h \text { (multi-t }\end{array}$ \\
\hline $\begin{array}{l}\text { Jawbone UP3, } \\
\text { Fitness Tracker }\end{array}$ & $\begin{array}{l}\text { Sleep stages (REM, light and deep), HR, } \\
\text { food and liquid intake, number of steps, } \\
\text { distance traveled, running }\end{array}$ & $\begin{array}{l}\text { Bluetooth } \\
\text { LE }\end{array}$ & Li-ion poly \\
\hline $\begin{array}{l}\text { Striiv Fusion Bio } \\
\text { Fitness Tracker }\end{array}$ & $\begin{array}{l}\mathrm{HR} \text {, number of steps, distance traveled, } \\
\text { calories burned, and sleep quality }\end{array}$ & $\begin{array}{l}\text { Bluetooth } \\
\text { LE }\end{array}$ & Li-ion , $3 \mathrm{c}$ \\
\hline Microsoft ${ }^{\bullet}$ Band 2 & $\begin{array}{l}\text { HR, calories burned, sleep quality, food, } \\
\text { and } \\
\text { liquid intake, number of steps, elevation, } \\
\text { climbing, running, biking. }\end{array}$ & Bluetooth & Li-poly, 2- \\
\hline $\begin{array}{l}\text { Fitbit Charge HR } \\
\text { Fitness Tracker }\end{array}$ & $\begin{array}{l}\text { HR, calories burned, sleep quality, food, } \\
\text { and } \\
\text { liquid intake, number of steps, elevation, } \\
\text { climbing, running. }\end{array}$ & $\begin{array}{l}\text { Bluetooth } \\
\text { LE }\end{array}$ & Li-poly, 5-6 \\
\hline $\begin{array}{l}\text { Garmin vivo smart, } \\
\text { HR Fitness Tracker }\end{array}$ & $\begin{array}{c}\text { HR, calories burned, sleep quality, } \\
\text { number } \\
\text { of steps, climbing, running, swimming }\end{array}$ & $\begin{array}{l}\text { Bluetooth } \\
\text { LE, ANT+ }\end{array}$ & Li-ion, 5-c \\
\hline
\end{tabular}

\section{Table 1, Listing of some commercial products for monitoring physiological signs and activities.}

Segment II depicts the associated work. Segment III examines engineering used for wearable remote cardiovascular infection observing framework. Segment IV examines remote system calculation for checking and recognizing cardiovascular ailment. Segment V depicts the usage and approval. Segment VI depicts the conclusion and future work.

\section{RELATED WORKS}

Adjacent positioned portable cardiovascular checking arrangement is represented in, which passions an framework of melded ECG beat discoverer, kept up by the PDA variation of Personal Health Information Management System and Simplified Correct Transfer Management System through remote framework. This system planned to use in home circumstance while the planned structure is capable to use for checking of the patients at different circumstances, for example, home, clinic, working places, essentially anyplace. A wearable cardiovascular [11] conditions for constant observing of client's heart state is presented [2], the planned framework is made out of 3 segments an expendable cathode, a controller, and individual (e.g., mobile phone, PDA, and PDA, and so on.). The ECG signs is verified by surface of body area potential. This framework is created to screen the ECG of the patient. While the proposed framework is proficient to ceaselessly screen patients in all positions, for example, portable, pc.

Gimenez et al. presents a framework for Essential people group cardiovascular restoration in view of mechanical stages for Existence Variation Secondary System. The Existence Variation Secondary System is constructed on a controller and decision support system (tablet-PC). The framework is associated different qualities: customized heart recovery program, programmed bolster in setting up and adjusting care program, hazard calculate, intensive care admittance for patients, concentrated cardiovascular checking through programmed attentions, encourage self-mind programs and constant data of the treatment comes about. The framework depicted in [3] is produced for the cardiovascular recovery reason, though the proposed framework is utilized for constant checking and ongoing cautioning of any heart issues for patients at any hazard level.

Hoff et al. display a gave ultrasound framework to screen cardiovascular capacity ceaselessly amid and after heart surgery. The ultrasound estimations are reinforced [4] by synchronous ECG and weight recordings. The proposed framework utilizes existing strategy for measuring of ECG, yet gets imaginative information gathering and ready scattering as indicated by hazard level every patient. This proposed structure gives the limit of expert to prescribe solution, by being anyplace.

Romero et al. depict assessment enhancement of heartbeat recognition calculation that is strong against abnormal amounts of clamor. An assessment convention is characterized with a specific end goal to study four distinct qualities of the calculation: non-cadenced examples, diverse stages of SNR, correct pinnacle identification and distinctive levels of physical action. The proposed system is used to extra human life by spreading cautions when the heart issue rises. This proposed system moreover gives the ability to locate the patient at danger and give the vital social security with minimum postponement.

\section{KEY CONTRIBUTION:}

The proposed system is fit for consistent, endless seeing of cardio vascular ailment, perceiving life undermining heart strikes, and disperses the alert to the pro, relatives, and patient. The correct now open wearable heart checking framework obliges availability to either cell system or remote system to disperse the caution. Yet, in the present situation, cell or remote system is not accessible ceaselessly. Because of this nonaccessibility of the system network, ready spread will be postponed, expanding the danger of the patient. Regardless of the possibility that the cell system is inaccessible, the proposed framework is fit to spread the alert to the patient through his wireless as high beep alarms or as sound messages. On gettogether of the high beep, the patient will get to be distinctly mindful of his/her wellbeing status and the required activity will be started.

An imaginative two stage ready spread is intended to give the medicinal services least deferral, adding to the lessening of risk to human life. Persistent information is gathered, totaled, and dispersed by wellbeing hazard. This will contribute in giving successful information movement administration.

The proposed framework is giving the capacity to screen the patient present at their work environment, home, healing center, and any place the patient wishes to be. In any case, the previously mentioned capacity of the framework gets new manysided quality of finding and following the patient. The proposed framework gives the answer for finding the patient continuously 
that will improve the ability of the framework in giving the required human services with least postponement.

This framework gives additional administrations to the specialist for nitty gritty examination of the accessible information and recommending the pharmaceutical by on the web, on his demand. This framework also gives availability patient's notable records by any dedicated selected by the patient.

\section{WIRELES NETWORK ACHITECTURE FOR MONITORING AND DETECTING CARDIOVASCULAR DISEASE}

The whole style for real time attention cardiovascular system is exposed in Figure 1. The construction involves:

\section{a) Wearable Wireless Sensor System:}

The wearable remote sensor framework utilized ceaselessly sense the ECG of patient. Wearable Wireless Sensor System comprises of lead mid-section terminals, circulatory strain sensors, signals preparing route, and the transmitter. Electrical signs started from heart caught by the dominant mid-section anodes, increased and separated utilizing the interfacing and signals handling route. The ECG signs are spread to the cell phone utilizing Bluetooth innovation.

The circulatory strain and breathing sensors equally be fused through framework. Information from sensors will checked when an ECG variation is noted. Relationship between three information will utilized to create a caution.

\section{b) Mobile Control System:}

The signs transmitted Wearable Wireless Sensor System are gotten by patient's phone. The cell phone goes about as regulatory framework, that handle the Ecg signals, produce underlying cautioning, and spread the information and alerting to the specialist, and patient's cell, furthermore to predetermined doctor's facility. The notice message with notice caution will send by the GSM/GPRS segment of the cell. Keeping in mind the goal to find the location of the patient, area, as of GPS module in the cell, and the time hallmark will have shown alongside every information bundle communication.

c)

Heterogeneous Wireless Network System:

The sign attention and detected information can spread to specialist and patient's cell, furthermore to predetermine doctor's facility utilizing heterogeneous remote system framework. The segments of the HWNS vary as indicated by the area of the patient. In the event that open air, he can pick specially appointed mode in his handling programming, and henceforth the information will be transmitted through the cell arrange. On the moldy chance that the patient home or in the healing facility, in which information can forward by remote local area network, broadband system, or satellite system. Those systems contained equally utilized for giving the upgraded administration to specialist, for example, conveying patient's records and existing signs for more examination analysis for controlling initiate specialist

\section{d) Two Phase Real-time Data Analysis and \\ Visualization System:}

The binary stage ongoing information examination and representation programming is utilized to convey quick and proficient cautioning/alarms cardiovascular patients to specialist and healing center. The primary stage actualized in portable monitor framework drive procedure the present ECG flags and direct ongoing notices. Another stage actualized in focal server farm. That stage will broad composite [12] examination drive
ECG signals accessible notable signs of patient, analyze the possibility of heart assault, or whatever further cardiac infections. That stage additionally proficient to convey the information investigation comes about alongside the ECG pictures to a specialist's cell phone, on his demand, at close continuous.

\section{e) Warning System}

The notice framework is coordinated in the portable control station furthermore in the focal server farm. The versatile control framework gives the quickest cautioning, though the focal server farm will give broad cautioning about any forthcoming cardiovascular illness. The notice caution can also a communication unique music put away in music collection of the troubled individual's cell, or a joined method.

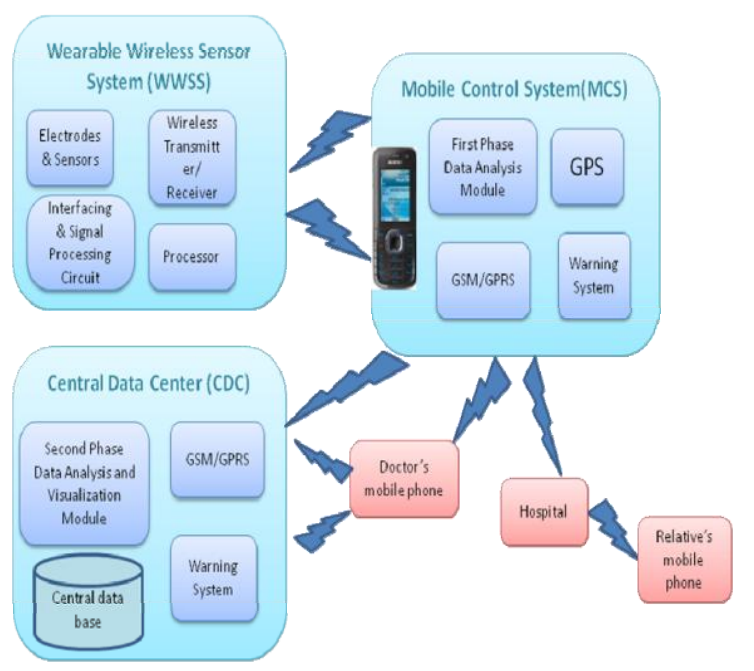

Figure 1: Wireless Network Architecture for Heart Attack Monitoring System

This engineering can be utilized for consistent checking cardiac patient's different specialists.

Major principle preferences framework is the accessibility to patient's notable information for new specialist. It helps in quicker and viable analyze of infection.

\section{WIRELESS NETWORK ALGORITHM PRINCIPLES FOR MONITORING AND DETECTING CARDIOVASCULAR DISEASE}

Distinctive remote system calculations are intended for preparing the got signals. These calculations are executed in the portable control station and in the focal server farm. The distinctive calculations are given underneath. 


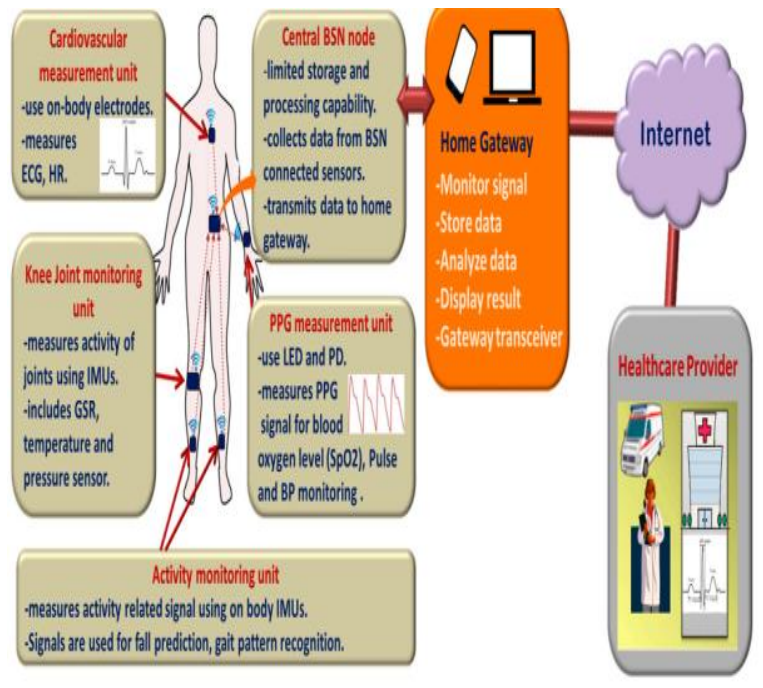

Figure 1: General overview of the remote health monitoring system.

\section{i. Algorithm for processing ECG Signal}

Flag gathered by the mid-section cathode must be handled to get ECG flag. This preparing of the ECG flag should be possible in Wearable Wireless Sensor System or in MCS in light of the power accessible to the Wearable Wireless Sensor System. Dynamic testing rate will be set by wellbeing danger of the individual.

\section{ii. Algorithm for analyzing ECG}

ECG signals got from the Wearable Wireless Sensor System will be dismembered in the MCS to pick the case changes that add to a particular cardiovascular torment. Any adjustment in the occasion that will trigger the information structure to switch on the weight and respiratory sensor. Relationship examination of data from these three sensors will be done. Any positive outcome from the examination will exhibit a notice level.A specific forewarning/masterminded message will be send to the ace, relative, understanding, and the recuperating center intrigue.

\section{iii. Risk Based Data Transmission Algorithm}

The sensor data transmission necessity for each patient will be particular according to their prospering peril. The thriving peril will be more, if a patient has formally experienced a heart ambush or having a basic cardiovascular ailment [13]. Each expert has given the capacity to set a base data transmission repeat in the MCS, as showed up by his patient's prosperity possibility. By and large, the central server property will effectively set a base information gathering recurrence as per the patient's noteworthy records. This base information gathering recurrence will be conveyed to the MCS amid the start of the system. The specialist can change the base information gathering recurrence as indicated by his carefulness and it will be conveyed to the MCS in close ongoing. The ECG motion from the MCS will be to send to the focal server farm as per already set information transmission recurrence.

\section{iv. Time synchronization}

ECG signals must be analyzed in the MCS and in the Central Data Center for picking the occasion continuum. This requires time synchronization concerning the general time for handy information examination. MCS and Central Data Center ought to be general time synchronized. Time synchronization in Wearable
Wireless Sensor System is capable by changing the MCS clock as per general time signals got from MCS, at reliable breaks.

\section{v. Locating the Patient}

Remote system structure gives the capacity to screen and find the patient dependably. The learning of patient's domain is crucial to give the required and healing activity with scarcest deferral. This can be capable by beginning GPS module in the MCS.

\begin{tabular}{|c|c|c|c|}
\hline Spatial Domain & Tempora| Domain & Frequency Domain & Statistical Domain \\
\hline Step length & Double support time & Spectral power & Correlation \\
\hline Stride length & Stance time & Peak Frequency & Mean \\
\hline Stepwidth & Step width Swing time & $\begin{array}{c}\text { Maximum spectral } \\
\text { amplitude }\end{array}$ & Standardd deviation \\
\hline RMS acceleration & Steptime & & Covariance \\
\hline Walkingspeed & Stride times & & skewness \\
\hline
\end{tabular}

Table 2. Features extracted from motion signal

\section{IMPLEMENTATION AND VALIDATION}

This ongoing remote observing and discovery framework for cardiovascular ailments will be actualized, tried, and approved, in the accessible heart patients. These patients will be joined with the [14 ]Wearable Wireless Sensor System to their body, on the mid-section. Their cell phones will be improved with the product stage created utilizing the above talked about plan, that will encourage effective and quick conveyance of notices.

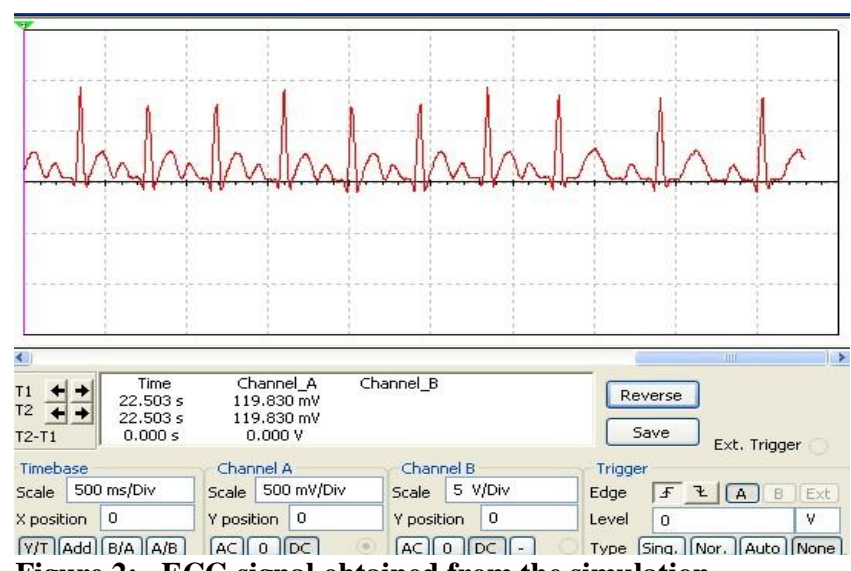

Figure 2: ECG signal obtained from the simulation

The hadware circuit for Wearable Wireless Sensor System was arranged and reenacted using NI Multisim1.0. One of the redirection results is showed up in Differentiating heart conditions were showed up in the diversion by changing the repeat and voltage. A QRS district figuring was used to see the assortments in the QRS complex. Right when this gathering crosses the edge for the patient, a notice will be issued. 


\section{CONCLUSION AND FUTURE WORK}

This paper exhibits a steady remote sensor oversee structure for checking and seeing any run of the mill cardiovascular sickness. The structure can screen differing patients in a flash, to pass on remote verification and game plans, other than to give rapid and appropriate warning to experts, relatives, and the recovering core interest. The structure setup incorporates wearable remote sensor focus, adaptable control unit, heterogeneous remote system framework, two stage information examination and perception framework, and the notice structure. The framework is additionally able to gather the information as indicated by observed thriving danger in every patient. Particularly this framework will be vital some time starting late, amidst, and after heart dissatisfaction for dependable seeing of a patient in the remote range. The structure will contribute in the diminishment of death in setting of heart catch and other cardiovascular issue; moreover, it can be utilized for giving succeeding relationship by particular experts. In addition, this framework can be passed on in trivial effort, since it on a very basic level needs to build up a wearable remote sensor structure, the thing makes, and the change of information stockpiling limit. The structure uses the open remote system for the information transmission, which adds to the cost decrease. In future, the present structure will be endeavored and caught on. The present structure will be changed later, by joining unmistakable sensors, to screen pulse, diabetes, and breathe process, to reduce false alerts.

\section{REFERENCES}

[1] K. W. Goh, J. Lavanya, Y. Kim, E. K. Tan, and C. B. Soh, "A pda based ECG beat detector for home

[6] S. Nimmala, J. van de Molengraft, J. Penders, and B. Gyselinckx, "An intelligent wireless ECG patch for single-lead ECG monitoring," Journal of Electro cardiology, vol.41, 2008, issue 6, pp. 645-646, doi:10.1016/j.jelectrocard.2008.08.031

[7] Brian Culshaw and Alan Kersey. Fiberoptic sensing: A historical perspective. Journal of Lightwave Technology, 26(9):1064-1078, 2008.

[8] Paulo Roriz, António Ramos, José L Santos, and José A Simões. Fiber optic intensity-modulated sensors: a review in biomechanics. Photonic Sensors, 2(4):315330, 2012.

[9] M. Xiuchen, L. Minzan, Z. Lihua, Z. Qin, and Z. Yao, Sensor Lett. 12, 883, 2014. cardiac care," $27^{\text {th }}$ Annual Conference Shanghai, IEEE. Engg. in Med And Biology, China, pp. 375378, September 1-4, 2005

[2] K. Shin, H. T. Hwang, H. Y. Kim, J. P. Kim, H. S. Yeo, and W. Han, "WHAM: A novel, wearable heart activity monitor based on Laplacian potential mapping," $27^{\text {th }}$ Annual Conference, IEEE. Engg. In Med and Biology, Shanghai, China, pp. 7361-7364. September 1-4, 2005.

[3] G. Gimenez, J. Guixeres, F. J. Villaescusa, J. Saiz, S. Merce, and R. Rodriguez, "A New System for Integral Community Cardiac Rehabilitation Based on Technological Platforms for the Lifestyle Change Supporting System," ISSN. Computers in Cardiology, pp. 845-848, 2006.

[4] H. Lars, E. Andreas, and I. Halfdan, "Cardiac Monitoring Using Transducers Attached Directly to The Heart," IEEE International Ultrasonic Symposium, pp. 749-752, 2008.

[5] R. Inaki, G. Bernard, and P. Julien, "Robust beat detector for ambulatory cardiac monitoring," 31 annual conferences of IEEE, EBMS. Minneapolis, Minnesota, USA, pp. 950-953, September 26, 2009.

[10] M Jeanne, F Narbonneau, J Witt, B Paquet, Damien Kinet, $\mathrm{K}$ Kreber, $\mathrm{R}$ Logier, et al. OFSETH: a breathing motions monitoring system for patients under mri. In Engineering in Medicine and Biology Society (EMBC), 2010 Annual International Conference of the IEEE, pages 1016-1019, 2010.

[11] Atzori, L and A .Iera. 2010. The internet of things: A survey Computer networks, 54(15), 2787-2805.

[12] M.M. A. Hashem, Rushdi Shams, Md. Abdul Kader, and Md. Abu Sayed, Design and Development of a Heart Rate MeasuringDevice using Fingertip, Department of Computer Science and Engineering Khulna University of Engineering \& Technology (KUET), Khulna 9203, Bangladesh, 2010

\section{Author Profile}

Tahzeeb ul Hassaan also member of IEEE in 2014 and senior member in 2017. Currently pursuing his( MS-CS ) degree in Signal and Information Processing at Department of Computer Science University of Agriculture Faisalabad Pakistan. He holds a Master (Information Technology) from GC University Faisalabad Pakistan. His research interests are on Wireless Sensor Network and embedded systems and Health monitoring in patient body, Wireless Security. Internet of things (IoT). Wireless Networks Intelligent information Processing.

Tahzeeb ul Hassan is also a Lecturer of Computer Science in( University of Central Punjab Faisalabad, Pakistan).Im also many publication in International journal in the domain of Computer Science and deep interest in Computer Networking with Wireless Sensor Network.

( Mubashir Tariq1,Sania Anwar,Noman Tahir, Muneeb Niaz, )is also my Publication Member. 